BIOTECHNOLOGY

\section{Embryo editing gets green light}

\author{
UK decision sets precedent \\ for research on editing \\ genomes of human embryos.
}

\section{BY EWEN CALLAWAY}

A team of scientists in London is preparing to edit the genomes of human embryos for research. The UK Human Fertilisation and Embryology Authority (HFEA) approved the work on 1 February in the world's first such endorsement. "It's an important first," says George Daley, a stemcell biologist at Boston Children's Hospital in Massachusetts. "This establishes a strong precedent for allowing this type of research."

The successful applicant is developmental biologist Kathy Niakan, at the Francis Crick Institute in London. Her team plans to use the CRISPR-Cas9 technique in healthy human embryos to alter genes that are active just after fertilization. The researchers will stop the experiments after seven days, when the embryos will be destroyed.

The genetic modifications could lead to treatments for infertility, but will not themselves form the basis of a therapy.

Robin Lovell-Badge, a developmental biologist at the Crick institute, says that the HFEA's decision will embolden other researchers. He has heard from other UK scientists who are interested in pursuing embryo-editing research, he says, and expects more applications to follow. Researchers also expect the decision to reverberate beyond the United Kingdom. "I think this will be a good example to countries who are considering their approach to regulating this technology," says bioethicist Sarah Chan at the University of Edinburgh, UK. "We can have a well-regulated system that is able to make that distinction between research and reproduction."

It remains illegal to alter the genomes of embryos used to conceive a child in the United Kingdom. But Tetsuya Ishii, a bioethicist at Hokkaido University in Sapporo, Japan, says that the HFEA decision could also stimulate debate over deploying embryo gene editing in clinical settings.

At a press briefing last month, Niakan said that her team could begin work within "months" of the HFEA approving the application. First,

\section{$\rightarrow$ NATURE.COM}

For a longer version of this story, see: go.nature.com/Isluwv however, a local research ethics board (similar to an US institutional review board) must approve the work.

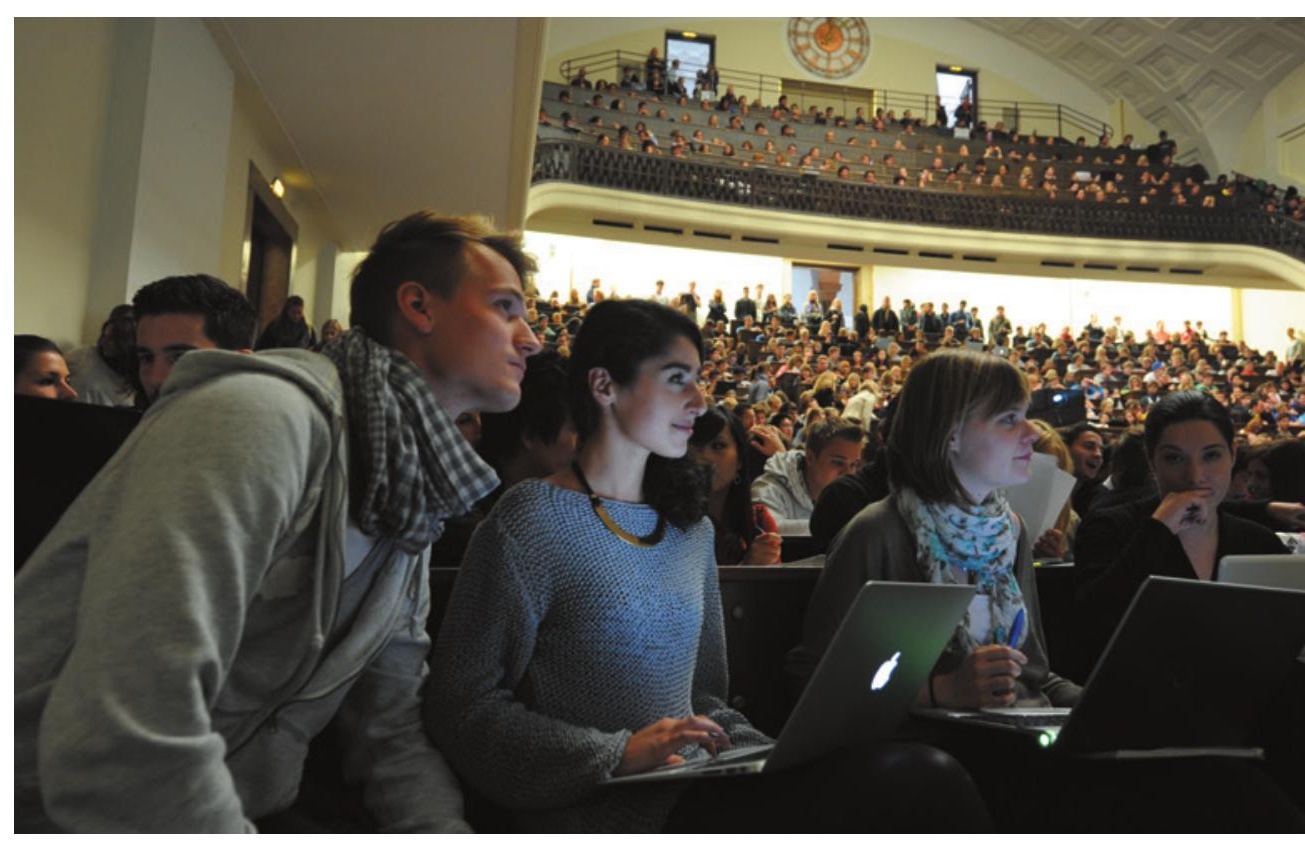

Ludwig Maximilian University of Munich is part of a government-backed 'cluster of excellence'.

GERMANY

\title{
Science hubs win in major revamp
}

\section{Research clusters emerge as the big success of Germany's} Excellence Initiative - despite its focus on elite institutes.

\section{BY QUIRIN SCHIERMEIER}

$\mathrm{F}$ Tor many, Munich's fame rests on the Oktoberfest beer festival. But for astrophysicist Stephan Paul, what makes the Bavarian capital so charming is its universities' rise to stardom in studies on the origin and structure of the Universe.

The region has long been a national hub for physics, but its appeal to theorists and particle physicists has soared in recent years thanks to a well-funded research programme that brings together the city's two large universities - the Technical University of Munich (TUM) and Ludwig Maximilian University (LMU) - and several Max Planck institutes in nearby Garching.

"The research infrastructure here is topnotch and the concentration of expertise is quite unique," says Paul, a physicist at the TUM who coordinates the programme.

The programme is one of 43 'clusters of excellence' launched in 2011 as part of Germany's €4.6-billion (US\$5-billion) Excellence Initiative. The clusters are among the ten-year-old initiative's most tangible successes, according to a major report released on 29 January by an independent, international panel (see go.nature.com/qxo768).

The hubs bring together research groups either within a university or across different institutes in the same region - that previously had little contact, so that they can pool their facilities and build on each other's successes. "We were surprised to find out how much good science there was just around the corner," says Paul.

The report, commissioned by Germany's federal government and its 16 state governments, strongly recommends that they continue the excellence initiative, in particular the highly successful clusters. The report is less conclusive on the initiative's success in achieving its much higher-profile goal: to produce a top-ranked research powerhouse akin to Harvard University or the universities of Oxford or Cambridge.

"The high quality of science produced at the clusters of excellence is particularly impressive," says Dieter Imboden, a Swiss environmental physicist and long-time science manager who chaired the evaluation panel. 
"But we are only at the beginning of a long road towards the group of global top universities."

Since it began, the initiative has designated a few universities as 'elite' - the latest assignment gave the status to 11 universities, including the TUM and the LMU - and rewarded them with an extra $€ 10$ million to $€ 14$ million per year. A report published last September by Germany's main research-funding agency, the DFG, noted that these 11 universities have markedly increased their scientific output. A further analysis done last year by Nature (Nature 525, 168-169; 2015) found that at elite institutions, the proportion of publications that feature in the top $10 \%$ of the world's most highly cited papers had almost doubled since 2002 (although Nature also found that the same was true on average of five good, but not elite, German universities).

But the new elite universities still lag far behind the likes of Oxford and Harvard in terms of world rankings, appeal to top scientists and funding. Critics of the initiative say that it has created a two-tier research system and an excessive administrative burden.

Even scientists at the 'elite' universities agree that the jury is still out on the success of the concept (see 'Germany's elite?'). "The initiative has created a palpable 'we can do it' spirit," says Stephan Leibfried, a social scientist and research-policy specialist at the University of

\section{GERMANY'S ELITE?}

A batch of 'elite' German universities received extra funds in 2011 - but the effect on the country's presence in world rankings is inconclusive.

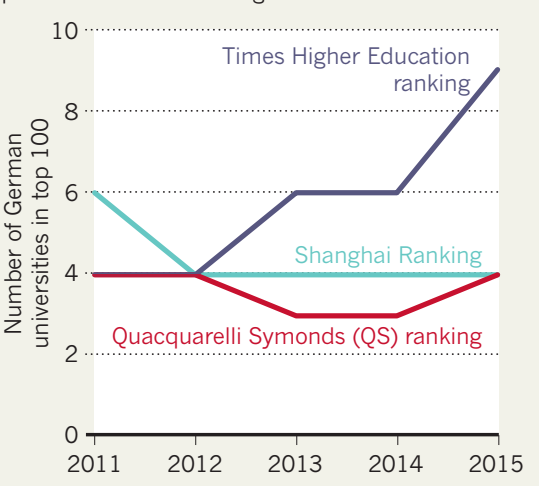

Bremen, which has elite status. But reaching the top of international university rankings "will require decades of hard work".

"No matter how often you might try, a Harvard can't be pulled, like a rabbit, out of the hat," agrees Stefan Hornbostel, a sciencepolicy researcher at the Humboldt University of Berlin, another of the latest 11 universities to be labelled elite.

The report recommends a two-year extension of the current programme, which ends in 2017, followed by a new programme starting in 2019.
It suggests that no more than 10 institutions should receive the elite bonus in the future, and that prolonged support of promising research clusters should be at the core of a renewed excellence programme. The report also says that in the follow-up regime, "smaller disciplines" deserve proportionally more funding than in the past and that research clusters could span geographically distant universities.

The recommendations are non-binding but are sure to feed into the decision of federal and state governments on whether to continue the initiative, which is due by June.

For Paul and his team, who have received some $€ 70$ million from the programme so far, the prospect of renewed support comes at the right time. Since 2006, some 150 physicists have moved from leading institutes in Europe and overseas to Munich. Researchers there have started to operate a newly built ultracold neutron facility and an underground laboratory largely shielded from background radiation, both financed in part with money from the initiative. Key experiments at these new facilities, says Paul, might shed light on the properties of neutrino particles, the design of the early Universe and the elusive nature of dark matter.

The collaborations enabled by the Excellence Initiative have produced some "good friction", he says. "Now we need to start using the heat." 


\section{CORRECTION}

The dollar conversion of $€ 4.6$ billion in the News story 'Science hubs win in major revamp' (Nature 530, 18-19; 2016) should have been US $\$ 5$ billion not $\$ 5$ million. 